\title{
Avaliação silvicultural e produtiva da Jatropha curcas (Linnaeus) no município de Cássia, MG
}

\author{
Silvicultural and productive evaluation of Jatropha curcas (Linnaeus) in the \\ municipality of Cássia, $M G$
}

\author{
Thiago Pinto Pires ${ }^{[a]}$, Magali Ribeiro da Silva ${ }^{[b]}$, Sylvio Péllico Netto ${ }^{[c]}$
}

[a] Engenheiro florestal pela Universidade Estadual Paulista - Júlio de Mesquita Filho (UNESP), câmpus de Botucatu, SP - Brasil, e-mail: thiagoppires@yahoo.com.br

[b] Engenheira florestal, Doutora, professora assistente da Universidade Estadual Paulista - Júlio de Mesquita Filho (UNESP), câmpus de Botucatu, SP - Brasil, e-mail: crrsilva@fca.unesp.br

[c] Engenheiro florestal, Doutor, professor titular da Pontifícia Universidade Católica do Paraná (PUCPR), São José dos Pinhais, PR - Brasil, e-mail: pellico.sylvio@pucpr.br

\section{Resumo}

A espécie Jatropha curcas (Linnaeus) pertence à família Euphorbiaceae, conhecida popularmente como pinhão-manso, com muitos atributos, múltiplos usos e um considerável potencial para a fabricação de biodiesel. O presente trabalho foi conduzido com o pinhão-manso, na Fazenda Reata, MG, em quatro experimentos, com o objetivo de avaliar a época da coleta das sementes, sua germinação, crescimento das mudas em viveiro e estrutura arbórea das árvores na fase adulta. A análise estatística experimental foi conduzida com aplicação de análise de variância e teste de Tukey para detecção de diferenças entre médias. Concluiu-se que as sementes atacadas pelo percevejo Pachycoris torridus, colhidas em março e abril, atingiram percentagens de germinação muito inferiores àquelas que não sofreram o ataque desse inseto, colhidas em janeiro. O tratamento que atingiu o melhor resultado (PG $=60 \%$ e VfG $=2,64 \mathrm{~s} / \mathrm{dia})$ foi o T1S3, cujas sementes foram colhidas em janeiro e com substrato terra $+20 \%$ esterco $+\mathrm{NPK}$; e o tratamento que atingiu a menor percentagem de germinação foi T3S2 ( $\mathrm{PG}=21,25 \%$ ), cujas sementes foram colhidas em abril e com substrato terra $+25 \%$ M.O. As sementes colhidas em março, independente do substrato utilizado, foram as que atingiram menores taxas de velocidade final de germinação. Os ensaios mostram a necessidade de um controle de pragas para a condução de plantios de pinhão-manso com fins de produção de sementes em áreas onde há a presença do $P$. torridus. O melhor substrato para o desenvolvimento do pinhão-manso foi o 3 (composto de terra $+20 \%$ esterco bovino + NPK - 0,3 $\mathrm{kg} \mathrm{m}^{-3}$ de super simples, $0,05 \%$ de cloreto de potássio). O experimento comprovou que as sementes coletadas em 
março e abril, após o ataque do percevejo $P$. torridus, além de apresentarem percentagens de germinação muito inferiores àquelas que não sofreram o ataque, deram origem também a indivíduos com menores taxas de crescimento. A planta de pinhão-manso no período caducifólio não apresenta diferença significativa na exudação de látex ao longo do dia. Como não houve correlação entre altura e o número de ramificações, isto significa que a quantidade de ramos que um indivíduo possui é um fator que pode ser selecionado geneticamente, com o fito de se aumentar futuramente a produção de sementes por indivíduo.

Palavras-chave: Pinhão-manso. Biodiesel. Germinação. Substrato.

\begin{abstract}
The species Jatropha curcas (Linnaeus) belongs to the family Euphorbiaceae, popularly known as pinhão-manso, with many attributes, multiple uses and considerable potential for biodiesel production. This work was conducted with the pinhão-manso, in the Reata Farm, MG, in four experiments to evaluate the time of collecting seeds, its germination, the growth of seedlings in nursery, and tree structure in adulthood. Statistical analysis was conducted with experimental implementation of ANOVA and Tukey test to detect differences between means. It was concluded that the seeds attacked by bedbug Pachycoris torridus, taken in March and April, germination percentages were much lower than those that had not been attacked by this insect, harvested in January. The treatment that had reached the best result ( $P G=60 \%$ and $V f G=2.64$ s/day) was the T1S3, whose seeds were collected in January and with substrate land $+20 \%+$ NPK dung; and the treatment that hit the lower germination percentage was T3S2 $(P G=21.25 \%)$, whose seeds were collected in April and substrate land $+25 \%$ M.O. Seeds harvested in March, regardless of substrate used, were those that reached the lowest rate of final germination speed. The tests showed the need for a pest control for conducting sprocket nut plantations with purposes of seed production in areas where there is the presence of $\mathrm{P}$. torridus. The best substrate for development from was the 3 (composed of ground beef manure $+20 \%+N P K-0.3 \mathrm{~kg} \mathrm{~m}^{-3}$ super simple, $0.05 \%$ potassium chloride). The experiment showed that the seeds collected in March and April after the attack of the bedbug P. torridus, besides their germination percentages were much lower than those which had not undergone the attack, also gave rise to individuals with lower growth rates. The plant of pinhão-manso in its broadleaf period did not have significant differences in latex exudation throughout the day as there was no correlation between height and the number of branches; this means that the amount of branches that an individual has is one factor that can be genetically selected, in order to increase future production of seed per individual.
\end{abstract}

Keywords: Pinhão-manso. Biodiesel. Germination. Substrate.

\title{
Introdução
}

A espécie Jatropha curcas (Linnaeus) pertence à família Euphorbiaceae e é conhecida popularmente como pinhão-manso, pinhão-de-purga, pinhão-de-cerca, purgueira, pinhão-paraguayo (DRUMMOND et al., 1984), pinhão-da-índia, pinhão-dos-barbados, mandobi-guaçu, figo-do-inferno (LORENZI et al., 2003). É uma espécie com muitos atributos, múltiplos usos e um considerável potencial. É considerada nativa da América tropical, no entanto, agora prospera em muitas áreas dos trópicos e subtrópicos da África e Ásia (OPENSHAW, 2000).

O pinhão-manso é um arbusto grande ou arvoreta decídua, lactescente, de 3-5 metros de altura, de aspecto suculento, de tronco com casca pardo-escura escamando em lâminas diminutas e finas. Apresenta folhas simples, ramagem longa, formando copa aberta e irregular (LORENZI et al., 2003). A primeira descrição ocorre na Flora Brasiliensis de Martius, publicada em 1874, na qual se registra a ocorrência de Jatropha curcas L. em Caldas, sul de Minas e nos arredores de Lagoa Santa, MG (MARTIUS; EICHLER; URBAN, 1874). Outras regiões onde o pinhão foi colhido no século XIX foram Rio de Janeiro, Bahia, Pará e Alto Amazonas. Renato Braga cita-o em 1976, no Ceará (COLETÂNEA..., 2003). 
O pinhão-manso é de fácil estabelecimento, cresce relativamente rápido, é rústico e tolerante a seca. Ele não é usado como forragem, por suas folhas e caules serem tóxicas aos animais, mas depois de efetuado um tratamento, as sementes ou sua torta podem ser usadas como alimentação animal. Várias partes da planta possuem valor medicinal, sua casca contém tanino, as flores são atrativas para abelhas e, consequentemente, a planta apresenta potencial melífero; sua madeira e fruto podem ser usados para numerosos propósitos, incluindo combustível (OPENSHAW, 2000).

O suprimento de J. curcas pode ser garantido pelos múltiplos propósitos de exploração da planta. As sementes são usadas como fonte de biocombustível (substituto para o óleo diesel), como adubo orgânico, ou em produção artesanal de sabão (HENNING; VON MITZLAFF, 1995). Também, como todas as árvores, ele fixa o carbono atmosférico, estoca-o na madeira e auxilia no aumento do carbono do solo (OPENSHAW, 2000). O fato de ser usado como biocombustível contribui para a diminuição da emissão de combustíveis fósseis e, consequentemente, do efeito estufa.

O pinhão-manso é tido como uma planta pouco atacada por pragas e doenças, entretanto, de acordo com Saturnino (2005), ataques severos do ácaro branco Polyphagotarsonemus latus Banks foram observados no mês de março de 2006 em Eldorado, MS, e Nova Porteirinha, MG. Segundo este mesmo autor, o pinhãomanso ainda pode ser atacado por ácaro vermelho, tripes, percevejos fitófagos (Pachicoris torridus), cigarrinha verde (Empoasca sp.) e cupins.

O óleo do pinhão-manso é considerado de secagem lenta, sem odor e incolor quando ainda fresco, mas se torna amarelo com o passar do tempo. O conteúdo do óleo das sementes varia de 30\% a 50\% do seu peso, e no caroço da semente varia de $45 \%$ a $60 \%$. Os ácidos graxos que compõem a semente do pinhãomanso são classificados como ácidos linoleico ou oleico, que são ácidos instaurados (PRAMANIK, 2002).

Segundo Gandhi et al. (1995 apud MENGUE et al., 2001), as sementes contêm uma proteína de ação tóxica, semelhante à ricina (presente na mamona, Ricinus cumunis L. também Euphorbiaceae). Além disso, o óleo presente nas sementes e o látex das partes aéreas da planta apresentam ação cáustica, podendo causar severa irritação na pele. Segundo Solsoloy (1995), extratos de J. curcas mostraram efeitos inseticidas contra pragas de cultivos como Helicoverpa armigera e Sitophilus zeamays. Já os pesquisadores Karmegam et al. (1997) provaram a ação tóxica contra vetores da filariose, tal como Culex quinquefasciatus.

Graças à alta produtividade da espécie em termos de porcentagem de óleo na semente, e ao crescente mercado de biocombustíveis no cenário mundial, existe a necessidade de aumentar os conhecimentos das características silviculturais do pinhão-manso.

\section{Material e métodos}

O presente trabalho foi conduzido com o pinhão-manso em quatro experimentos, visando a avaliar a época da coleta das sementes, sua germinação, crescimento das mudas em viveiro e estrutura arbórea delas.

\section{Experimento 1 - Avaliação da germinação do pinhão-manso em diferentes substratos com diferentes épocas de coletas de sementes}

O experimento foi realizado com o objetivo de avaliar o efeito de substratos e lotes de sementes sobre a germinação do pinhão-manso. Esse foi realizado na propriedade denominada Fazenda Reata, localizada no município de Cássia, região sul do Estado de Minas Gerais, situada na latitude $20^{\circ} 20^{\prime}$ e $20^{\circ} 40^{\prime}$ Sul e longitude $46^{\circ} 40^{\prime}$ e $47^{\circ} 00^{\prime}$ Oeste (CORAIOLA, 1997).

A região de Cássia está situada a aproximadamente $680 \mathrm{~m}$ de altitude e apresenta temperaturas médias anuais de $26,5^{\circ} \mathrm{C}$ (máxima) e $19,5^{\circ} \mathrm{C}$ (mínima). O clima da região, segundo Köppen, é do tipo Cwa (tropical de altitude), apresentando verões rigorosos e chuvosos (CORAIOLA; PELICO NETTO, 2003).

As sementes usadas no experimento foram coletadas nos meses de janeiro, março e abril de 2008, em plantações com idade de dois anos localizadas na própria Fazenda Reata, e foram armazenadas dentro 
de sacarias em um galpão coberto e com baixa incidência de luz solar. As sementes que deram origem aos indivíduos das plantações da referida propriedade são procedentes do Estado do Mato Grosso.

Para a instalação do experimento foi necessária a construção de um viveiro, iniciada em $1^{\circ}$ de agosto. Foi construída uma casa de sombra, utilizando-se mourões de eucaliptos como estrutura e tela de sombreamento 70\% para cobertura e proteção lateral, homogeneizando as condições de temperatura e luminosidade no interior da casa de sombra. Para a estruturação dos canteiros foram utilizadas varas de bambu, conforme está mostrado nas Figuras 1 e 2.

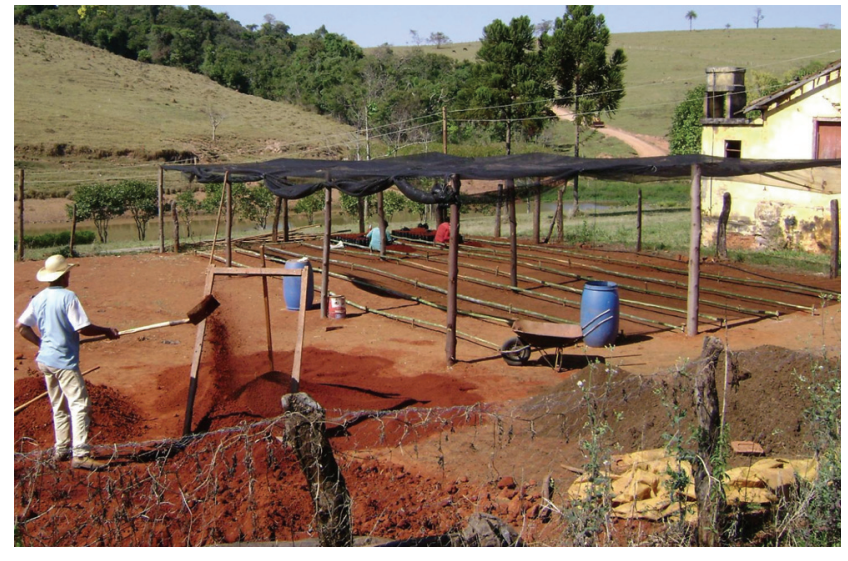

Figura 1 - Preparo do solo ao lado Casa de Sombra

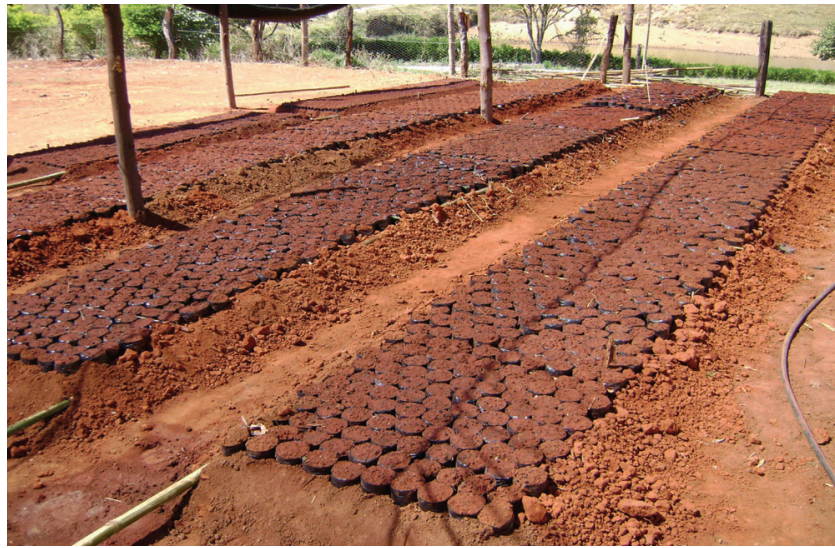

Figura 2 - Canteiros com embalagens prontas

Após o término da construção do viveiro, iniciou-se o processo de preparo dos diferentes substratos para compor o experimento. Foi utilizado solo peneirado de textura argilosa, coletado em subsolo, e esterco bovino após um período de compostagem.

O delineamento experimental adotado obedeceu a um esquema fatorial de $3 \times 3$ (sementes de três épocas de coleta e três tipos de substrato), totalizando nove tratamentos com quatro repetições de 100 sementes cada um deles. As épocas de coleta das sementes foram: janeiro, março e abril de 2008. E os substratos foram: $\mathrm{S} 1$ = terra de subsolo; S2 = terra de subsolo + esterco bovino $(3: 1)-25 \%$ M.O.; e S3 = terra de subsolo + NPK+ esterco bovino (4:1) - 20\% M.O.

O experimento teve uma distribuição inteiramente casualizada, conforme se pode verificar nas Figuras 3 e 4.

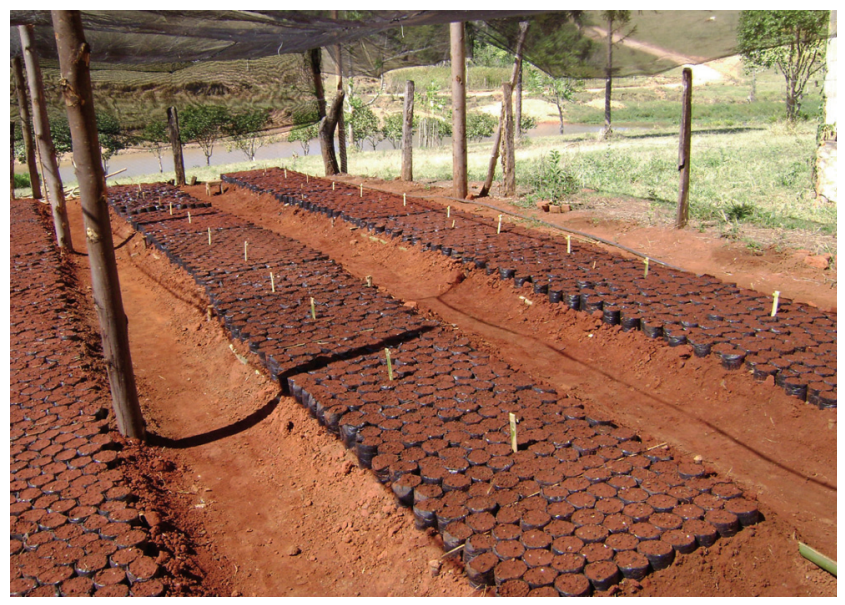

Figura 3 - Visualização da distribuição das repetições

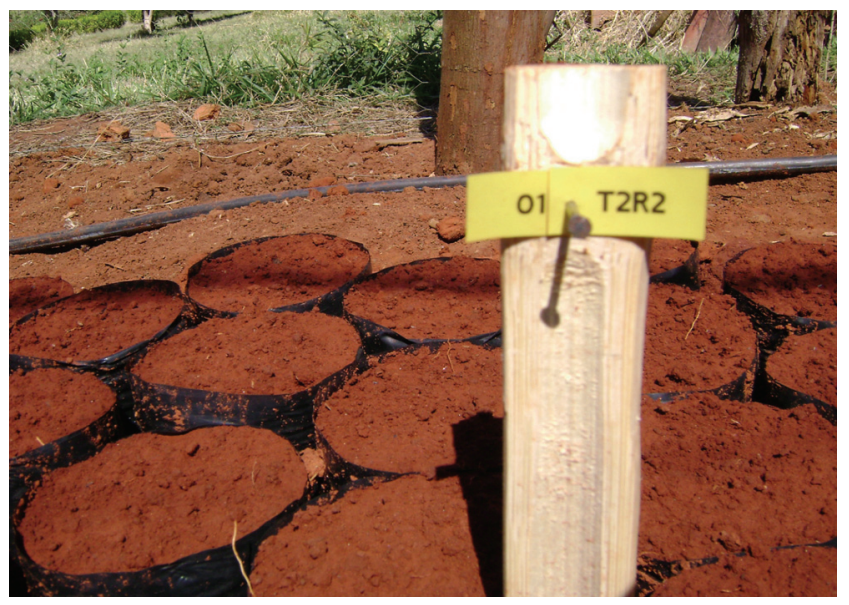

Figura 4 - Visualização da anotação adotada 
A semeadura foi feita no dia 18 de agosto de 2008 e as avaliações de germinação ocorreram diariamente a partir do dia seguinte à semeadura.

Foram considerados como indivíduos germinados aqueles que apresentaram o aparecimento do hipocótilo, conforme está ilustrado na Figura 5.

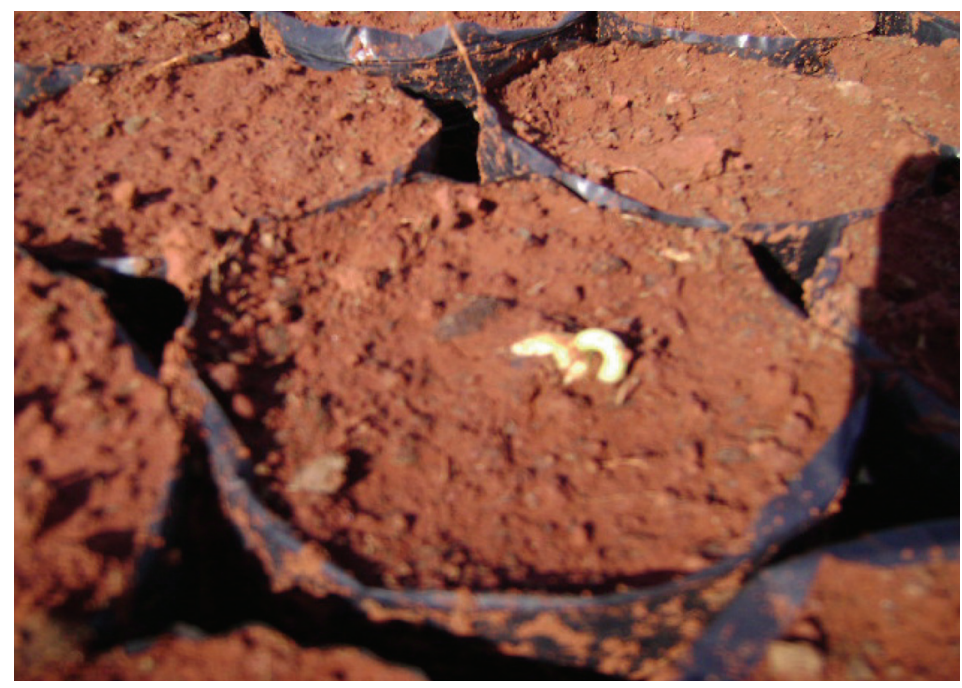

Figura 5 - Detalhe da germinação

Os parâmetros avaliados foram a porcentagem de germinação e a velocidade final de germinação. Para avaliar esses parâmetros foram utilizadas, respectivamente, as fórmulas 1 e 2 :

em que:

$$
\mathrm{PG}=(\mathrm{N} / \mathrm{A}) \times 100
$$

$\mathrm{N}=$ número de sementes germinadas;

$\mathrm{A}=$ número de sementes da amostra.

VfG = número total de sementes germinadas / número total de dias observados

Os dados de porcentagem de germinação foram submetidos à análise de variância e as médias dos tratamentos com diferenças significativas pelo teste " $F$ " foram comparadas pelo teste de Tukey.

\section{Experimento 2 - Influência da época de coleta de sementes e de substratos no crescimento do pinhão-manso}

Este experimento teve por objetivo a continuidade do experimento 1 e avaliar, durante quatro semanas, o crescimento das mudas.

Os indivíduos oriundos do experimento 1 (germinação) tiveram suas alturas e diâmetros medidos durante quatro semanas. As medições ocorreram semanalmente, a partir do momento em que as plântulas se estabeleceram e começaram a emitir as primeiras folhas, conforme se pode observar na Figura 6. Para a avaliação foram utilizados uma régua e um paquímetro, conforme está mostrado na Figura 7.

Neste experimento foi aplicado o mesmo delineamento amostral do experimento 1, com os três substratos diferentes, sendo eles: 1 - terra; 2 - terra $+25 \%$ esterco de bovino; e 3 - terra $+20 \%$ esterco + NPK, e com as três diferentes épocas de coleta de sementes: janeiro, março e abril. 

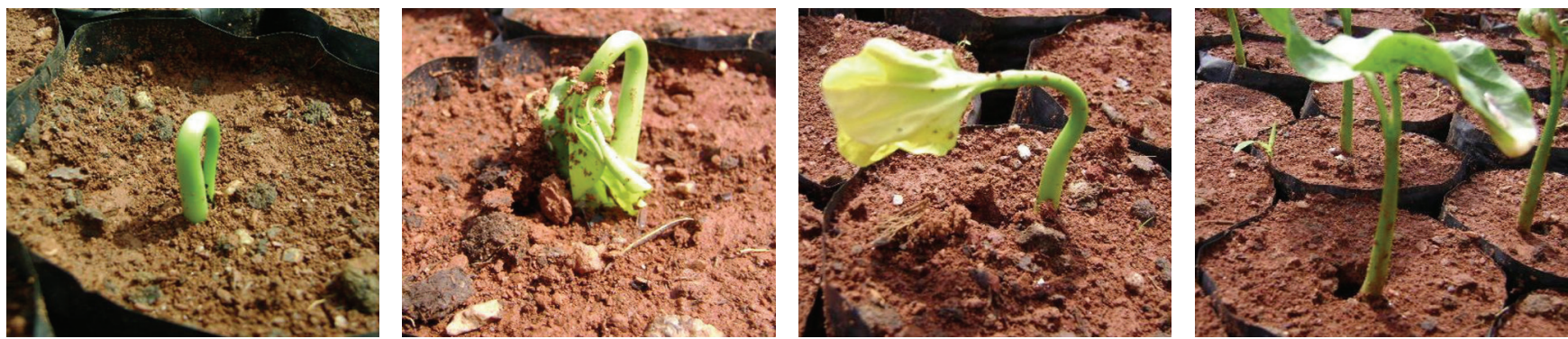

Figura 6 - Processo pós-germinativo do pinhão-manso
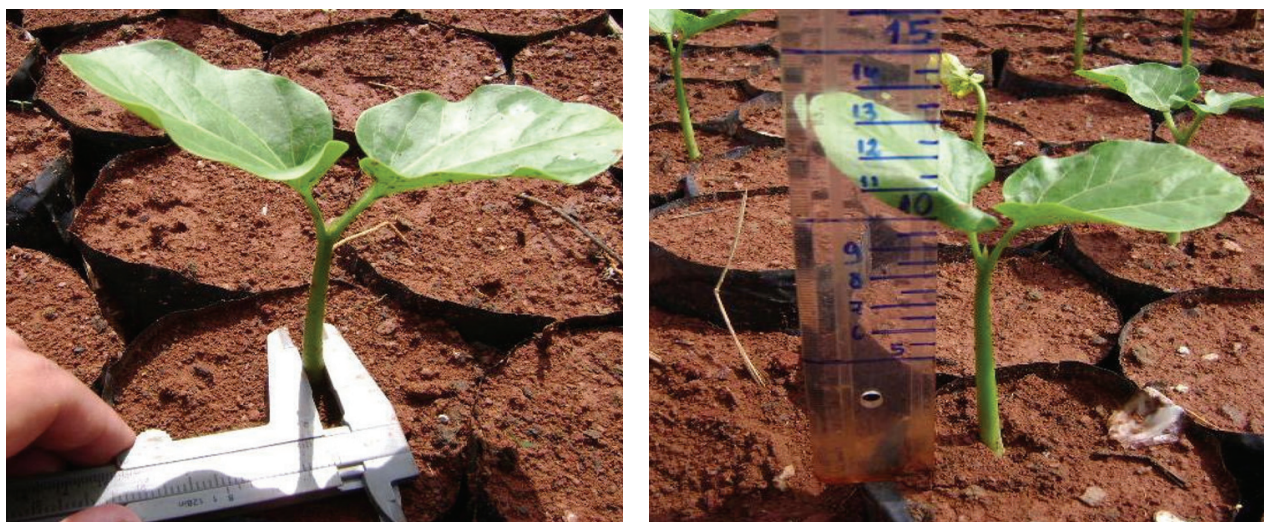

Figura 7 - Detalhe do esquema de medição do diâmetro e da altura, respectivamente

As medições das 1.082 plantas ocorreram nos dias 11, 18 e 25 de setembro e 3 de outubro de 2008. Os dados foram processados e apresentados em diferentes gráficos para comparar os crescimentos dentro de cada fator analisado. A comparação de médias foi efetuada por meio de análise de variância, pelo software SigmaStat ${ }^{\circledR}$.

\section{Experimento 3 - Produção de látex de pinhão-manso em diferentes horários ao longo do dia}

Este experimento teve por objetivo avaliar o efeito do horário de coleta sobre a produção de látex do pinhão-manso, e foi realizado na propriedade Fazenda Reata, localizada no município de Cássia, MG.

A produção de látex foi medida em quatro horários do dia: 8h, 11h, 13h e 16h. Foram analisados dez indivíduos de uma plantação com dois anos de idade, com um mesmo padrão morfológico e uma altura em torno de dois metros. A coleta foi realizada no mês de agosto de 2008, durante a fase caducifólia da cultura.

Para a extração foi feita uma incisão vertical no tronco, com um canivete, a uma altura de mais ou menos $20 \mathrm{~cm}$ do solo. Para coletar o material foram utilizados copos plásticos descartáveis, e para a quantificação do líquido foi utilizada uma proveta milimetrada. Os copos descartáveis foram deixados durante uma hora na base da planta para coletar o látex; esse tempo foi o suficiente para a estagnação da exudação.

\section{Experimento 4 - Medição das ramificações e alturas totais dos indivíduos de pinhão- manso no campo}

Este experimento teve por objetivo medir altura e números de ramificações de indivíduos de pinhãomanso com dois anos de idade. 
A medição ocorreu em uma plantação da espécie, com dois anos de idade, também localizada na Fazenda Reata, em Cássia, MG.

A plantação possui um espaçamento médio de $3 \mathrm{~m} \times 2,5 \mathrm{~m}$, e a cada dez metros foi plantada uma espécie florestal com madeira nobre característica da região, como Jatobá, Bálsamo, Cedro, Saguaraji, Guaritá, entre outras.

Dentro da plantação existem três parcelas amostrais distribuídas de forma aleatória, sendo parcela 1 com área de 1 ha, parcela 2 com 0,5 ha e parcela 3 com 0,5 ha, totalizando um total de 2 ha.

Foram medidos o número de ramificações até uma altura de $50 \mathrm{~cm}$ do solo e a altura total de 1.935 indivíduos presentes nas três parcelas.

Para a medição, foi utilizada uma vara graduada de 3 metros de altura (Figura 8).



Figura 8 - Ilustração do sistema de medição utilizado

Foram calculadas as médias, o desvio padrão, o coeficiente de variação e a correlação entre altura e número de ramificações (Figura 9).
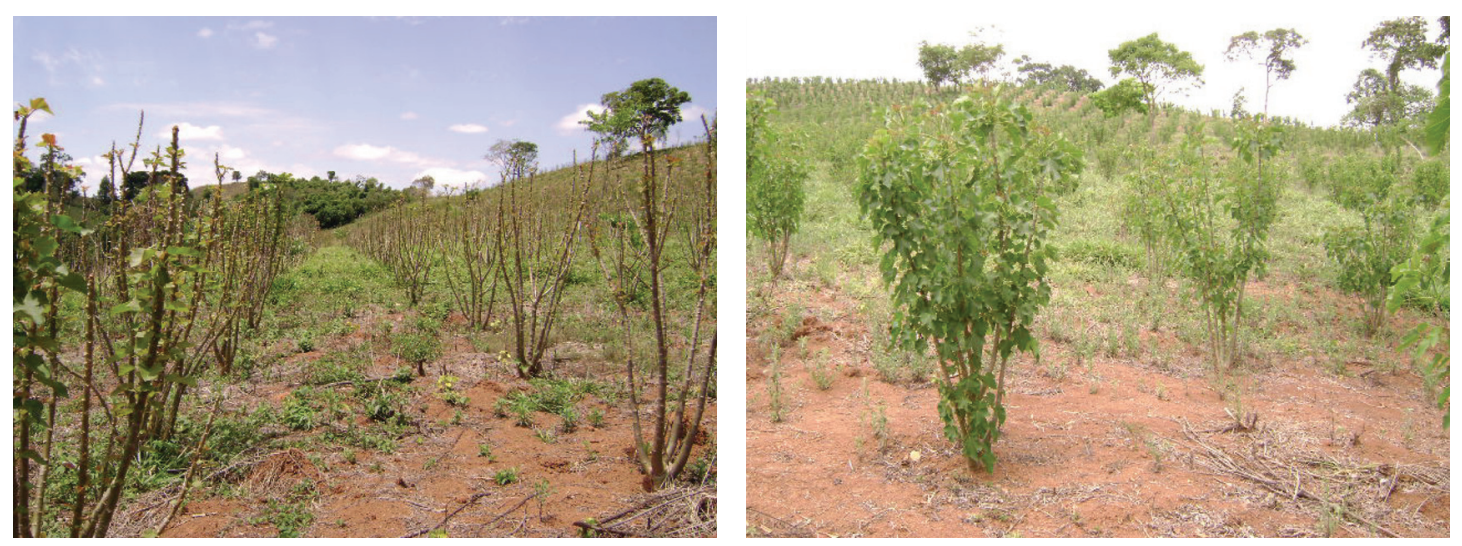

Figura 9 - Detalhes da área estudada 


\section{Resultados}

\section{Resultados e discussões do experimento 1}

As sementes começaram a germinar a partir do oitavo dia do plantio, dado idêntico ao de Carvalho, Castro e Cândido (2007).

Antes da aplicação da análise de variância, foi realizado o teste de Hartley para verificar a heterogeneidade de variância, e este se mostrou não significante a 95\% de probabilidade; ou seja, as variâncias são homogêneas. Com relação à porcentagem de germinação, houve uma diferença significativa entre todos os fatores analisados, conforme demonstra a Tabela 1.

Tabela 1 - Análise de variância da porcentagem de germinação

\begin{tabular}{lcrrrrr}
\hline Fonte & g1 & SQ & MQ & F & F crítico & \\
\hline Tratamento & 8 & 5835,56 & 729,44 & $21,44^{* *}$ & F8;27;0,01 & 3,26 \\
T. de Coleta & 2 & 4354,06 & 2177,03 & $63,98 * *$ & F2;27;0,01 & 5,49 \\
Substrato & 2 & 718,39 & 359,19 & $10,56 * *$ & F2;27;0,01 & 5,49 \\
(TXS) & 4 & 763,11 & 190,78 & $\mathbf{5 , 6 1 * *}$ & F4;27;0,01 & $\mathbf{4 , 1 1}$ \\
Resíduo & 27 & 918,75 & 34,03 & & & \\
Total & 35 & 6754,31 & & & & \\
\hline
\end{tabular}

Como pode ser observado na Tabela 1, o valor de F encontrado para todas as fontes (tratamento, tempo de coleta, substrato e interação substrato $\times$ tempo de coleta) foi maior que o valor de F crítico, a 99\% de probabilidade, o que confirma a alta significância estatística entre os fatores analisados.

A comparação entre as médias foi efetuada pela aplicação do Teste de Tukey, cujos resultados encontram-se apresentados na Tabela 2.

A Tabela 2 demonstra a relação de significância entre os fatores, evidenciando que os tratamentos T2S1, T2S2, T2S3, T3S1, T3S2 e T3S3 não foram diferentes entre si. A significância mais expressiva se expressou entre os tratamentos T1S1 e T1S3 e os demais, a 99\% de probabilidade.

Encontram-se apresentados na Tabela 3 os resultados de percentagem de germinação comparados pelo teste de Tukey dentro dos fatores analisados, ou seja, entre substratos nas diversas épocas de coleta das sementes e entre os períodos de coleta dentro de cada um dos substratos utilizados.

As sementes coletadas no mês de janeiro plantadas no substrato composto de solo + esterco $+\mathrm{NPK}$ (S3) apresentaram a maior média de germinação, 60\%. Esse valor pode ser considerado baixo se comparado às porcentagens de germinação de sementes de pinhão-manso coletadas em Santa Vitória e Janaúba, MG, submetidas à avaliação de germinação por Carvalho et al. (2007), que conseguiram obter taxas de $81,6 \%$ e $84 \%$ de germinação respectivamente.

Considerando o fator sementes dentro de cada substrato, observou-se que no substrato 3 a germinação foi estatisticamente superior, quando usada a semente de janeiro. As sementes de março e abril resultaram em valores semelhantes entre si. Nos demais substratos, embora sempre a semente de janeiro tenha obtido os melhores resultados, o efeito não foi tão pronunciado. No substrato S1, as sementes de janeiro e abril foram semelhantes estatisticamente, e no substrato 2, sementes de janeiro de março não diferiram entre si.

Ao analisar o efeito de substrato para cada lote de sementes, observa-se que quando usadas as sementes de março ou abril, o substrato não influenciou na porcentagem de germinação. Já para as sementes de janeiro, o melhor resultado foi no substrato S3, porém não diferindo estatisticamente de S1. 
Tabela 2 - Relações de significância entre os fatores

\begin{tabular}{|c|c|c|c|c|c|c|c|c|c|c|}
\hline & & 21,25 & 21,50 & 23,25 & 23,25 & 29,25 & 34,75 & 36,50 & 48,50 & 60,00 \\
\hline & & T3S2 & T2S1 & T2S2 & T2S3 & T3S3 & T3S1 & T1S2 & T1S1 & T1S3 \\
\hline 21,25 & T3S2 & - & $\mathrm{ns}$ & $\mathrm{ns}$ & ns & $\mathrm{ns}$ & ns & * & $* *$ & $* *$ \\
\hline 21,50 & T2S1 & & - & ns & ns & ns & ns & * & $* *$ & $* *$ \\
\hline 23,25 & T2S2 & & & - & ns & $\mathrm{ns}$ & ns & $\mathrm{ns}$ & $* *$ & $* *$ \\
\hline 23,25 & T2S3 & & & & - & ns & ns & ns & $* *$ & $* *$ \\
\hline 29,25 & T3S3 & & & & & - & ns & ns & $* *$ & $* *$ \\
\hline 34,75 & T3S1 & & & & & & - & ns & ns & $* *$ \\
\hline 36,50 & T1S2 & & & & & & & - & ns & $* *$ \\
\hline 48,50 & T1S1 & & & & & & & & - & ns \\
\hline 60,00 & T1S3 & & & & & & & & & - \\
\hline
\end{tabular}

Nota: $\mathrm{T} 1=$ janeiro; $\mathrm{T} 2=$ março; $\mathrm{T} 3=$ abril; $\mathrm{S} 1, \mathrm{~S} 2$ e S3 $=$ substratos 1,2 e 3

ns = não significativo; $\mathrm{W}_{0,05}=13,77 ; \mathrm{W}_{0,01}=16,50$

$*=$ significante a $5 \%$

$* *=$ significante a $1 \%$.

Tabela 3 - Percentagem de germinação dentro de cada fator analisado

\begin{tabular}{llll}
\hline \multirow{2}{*}{ Substrato } & \multicolumn{3}{c}{ Sementes } \\
\cline { 2 - 4 } & Janeiro & Março & Abril \\
\hline S1 & 48,5 a AB & $21,5 \mathrm{~b} \mathrm{~A}$ & $34,75 \mathrm{ab} \mathrm{A}$ \\
S2 & $36,5 \mathrm{a} \mathrm{B}$ & $23,25 \mathrm{ab} \mathrm{A}$ & $21,25 \mathrm{~b} \mathrm{~A}$ \\
S3 & $60,0 \mathrm{a} \mathrm{A}$ & $23,25 \mathrm{~b} \mathrm{~A}$ & $29,25 \mathrm{~b} \mathrm{~A}$ \\
\hline
\end{tabular}

Nota: Médias seguidas de letras iguais minúsculas nas linhas e maiúsculas nas colunas não diferem ao nível de $5 \%$ pelo teste de Tukey.

Os resíduos orgânicos, como o esterco bovino, são pouco estudados quanto às características físicoquímicas, bem como as quantidades a serem aplicadas nas culturas como fertilizante principal ou associado à adubação mineral. O fato do substrato 2 apresentar um valor de 5\% a mais de matéria orgânica que o substrato 3 pode explicar a diferença significativa entre eles. Em virtude de ambos receberem o mesmo regime hídrico, o substrato 2 apresentou visivelmente maior concentração de água; isto se deve à maior quantidade de M.O., que contribui para retenção de água. Esse processo influenciou diretamente a aeração do substrato e, consequentemente, pode ter acelerado o processo de degradação das sementes.

Todas as sementes coletadas nos meses de março e abril resultaram em médias de germinação muito baixas e não apresentaram diferenças significativas entre si, sendo que os três substratos experimentados para esses dois lotes de sementes não influenciaram na germinação. 
Analisando o histórico da plantação no campo em que foram coletadas as sementes do experimento, observou-se que a partir do mês de fevereiro de 2008 houve um ataque generalizado de um percevejo em toda a plantação, identificado como Pachycoris torridus (Scopoli).

P. torridus é a espécie mais conhecida da família Scutelleridae no Brasil (GALLO et al., 1988), sendo constatado em araçazeiro (Psidium araça), arroz (Oryza sativa), cajueiro (Anacardium occidentale), eucalipto (Eucalyptus sp.), goiabeira (Psidium guajava), laranjeira (Citrus sinensis), mandioca (Manibot esculenta), mangueira (Mangifera indica), pinhão-manso (Jatropha curcas) e tungue (Aleurites fordii) (SILVA et al., 1968).

Conhecido vulgarmente no Brasil como percevejo-do-pinhão-bravo (SILVA et al., 1968), é uma espécie com ampla distribuição na América, sendo registrada desde os Estados Unidos (Califórnia) até a Argentina (FROESCHNER, 1988). Do mesmo modo que outras espécies da família Scutelleridae (SCHUH; SLATER, 1995), P. torridus apresenta ampla variabilidade nos desenhos e cores do seu corpo (MONTE, 1937), o que levou a espécie a ser descrita oito vezes como nova (COSTA LIMA, 1940). De acordo com Monte (1937), a forma mais frequente desse percevejo é a que apresenta colorido básico preto ou vináceo escuro, com pontuações finas, cabeça escura, pronoto e escudo com 22 manchas (8 no pronoto e 14 no escudo) vermelhas ou amareladas. A parte ventral do corpo é verde metálico. As pernas são escuras com reflexos esverdeados. Segundo Bondar (1913), o percevejo mede de 12 a $14 \mathrm{~mm}$ de comprimento e de 8 a $9 \mathrm{~mm}$ de largura (SOTO et al., 2004).

Segundo Mato Grosso do Sul - Brasil (apud SATURNINO, 2008), os principais prejuízos oferecidos por esse percevejo são nas sementes, acarretando menor peso, menor teor de óleo e baixo poder germinativo. Isso prova as diferenças significativas com o lote de sementes do mês de janeiro e explica as baixas porcentagens de germinação nos meses de março e abril, que vieram após o ataque dessa praga. Visualizações da diversidade de coloração dos percevejos e do seu ataque em frutos do pinhão-manso estão apresentadas nas Figuras 10 e 11.

Segundo Severino; Lima e Beltrão (2006), as sementes de pinhão-manso mais pesadas possuem maior poder germinativo e geram plantas com emergência e crescimento inicial mais rápido.

As velocidades finais de germinação foram calculadas (Tabela 4) e notam-se maiores velocidades de germinação nas sementes coletadas no mês de janeiro, seguido por abril, e tendo o mês de março as menores velocidades finais - o que evidencia que o ataque do inseto $P$. torridus, além de causar baixas taxas de germinações, diminuiu também as velocidades de germinação.



(a)

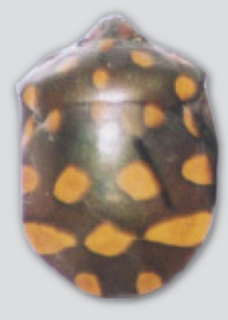

(e)

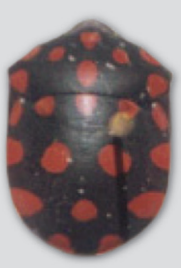

(b)

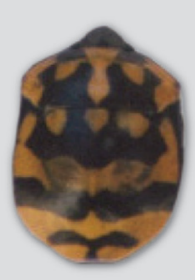

(f)



(c)

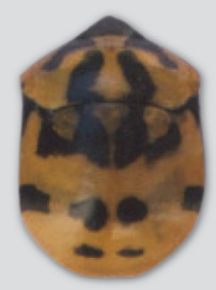

(g)

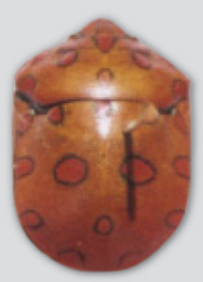

(d)

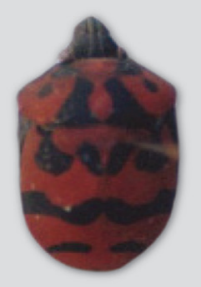

(h)

Figura 10 - Variação de cores e padrão de manchas do P. Torridus, SOTO et al., 2004 


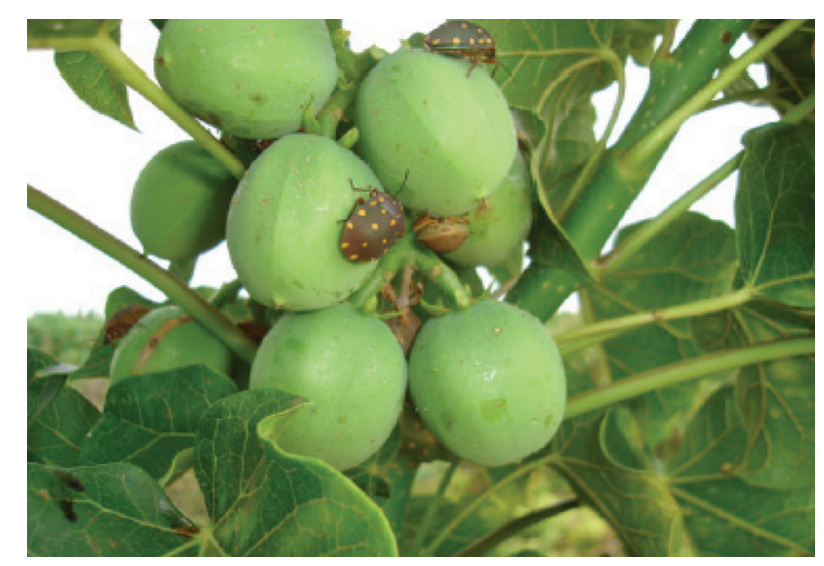

Figura 11 - Detalhe do ataque do percevejo P. torridus

Tabela 4 - VfG em número de sementes germinadas por dia

\begin{tabular}{lccc}
\hline Meses & Substrato 1 & Substrato 2 & Substrato 3 \\
\hline Janeiro & 1,54 & 1,63 & 2,64 \\
Março & 0,78 & 0,95 & 0,82 \\
Abril & 1,61 & 1,08 & 1,22 \\
\hline
\end{tabular}

O Gráfico 1 mostra a tendência das velocidades instantâneas no tempo gasto para ocorrer a germinação total de uma das repetições.

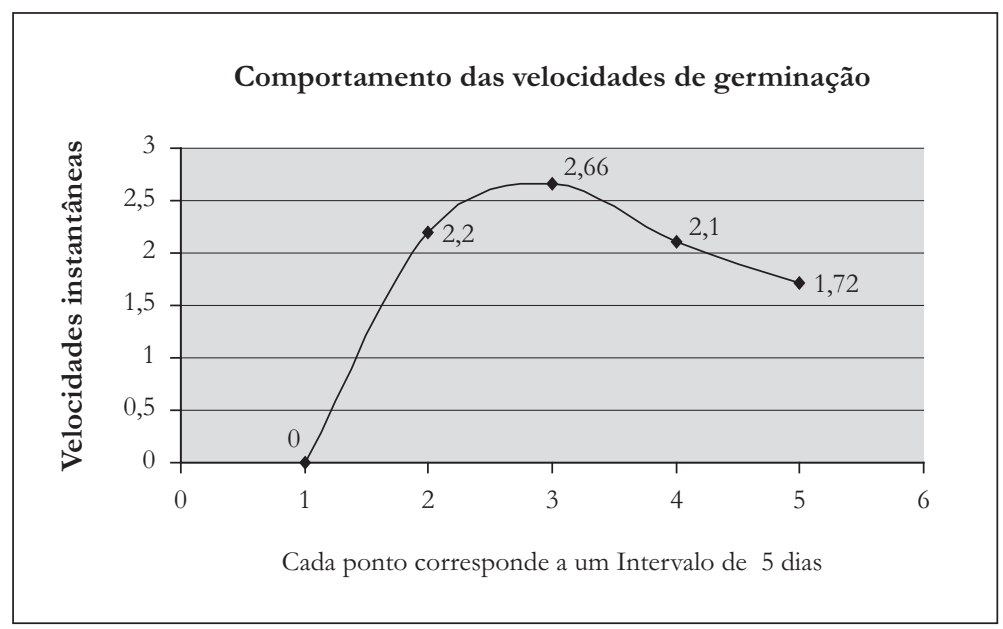

Gráfico 1 - Velocidade de germinação ao longo do tempo

Foi observado o mesmo comportamento de ascensão e declínio para as demais repetições. Os dados das velocidades de germinação serão posteriormente submetidos a uma análise de variância para verificar a significância dos resultados. 


\section{Resultados do experimento 2}

Como podem ser observados nos Gráficos 2, 3 e 4, os substratos influenciaram de forma significativa o crescimento das mudas, independente da semente usada. O substrato S1 resultou no menor desempenho. Os substratos 2 e 3 atingiram um crescimento semelhante até a terceira semana, quando o substrato 3 se diferencia por uma aceleração no crescimento em altura, com destaque pelas maiores médias finais de crescimento, evidenciando a importância do adubo a partir desta fase e demonstrando que, apesar da espécie ser considerada rústica e de crescimento rápido, ela responde à adubação orgânica e química.

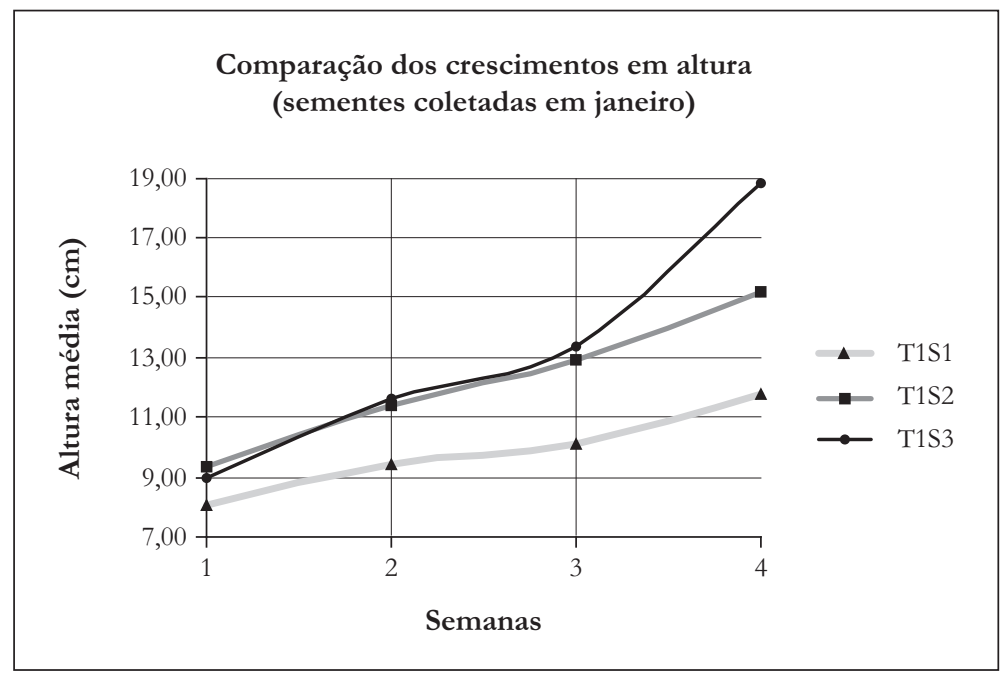

Gráfico 2 - Crescimento em altura das mudas advindas das sementes de janeiro, ao longo de quatro semanas

Nota: T1: sementes colhidas em janeiro, S1: Substrato terra - 1; S2: Substrato terra $+25 \%$ esterco - 2; S3: Substrato terra $+20 \%$ esterco + NPK -3.



Gráfico 3 - Crescimento em altura das mudas advindas das sementes de março, ao longo de quatro semanas

Nota: T2: sementes colhidas em março, S1: Substrato terra - 1; S2: Substrato terra $+25 \%$ esterco - 2; S3: Substrato terra $+20 \%$ esterco + NPK -3. 


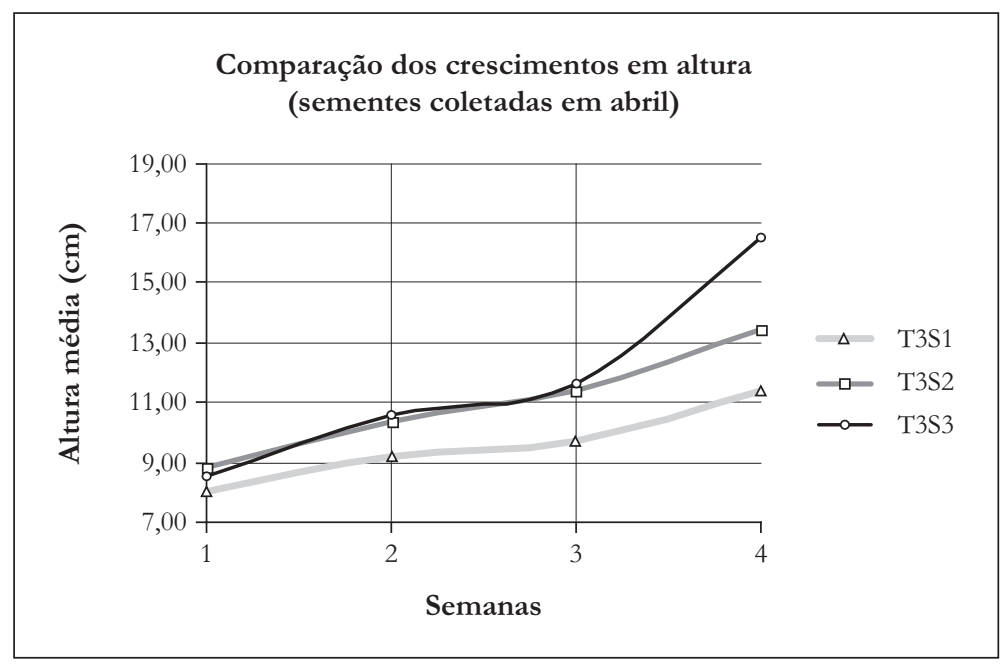

Gráfico 4 - Crescimento em altura das mudas advindas das sementes de abril, ao longo de quatro semanas

Nota: T3: sementes colhidas em abril, S1: Substrato terra - 1; S2: Substrato terra $+25 \%$ esterco $-2 ;$ S3: Substrato terra $+20 \%$ esterco + NPK -3.

Como pode ser observado no Gráfico 5, o substrato 3 apresentou as maiores alturas totais, e as sementes coletadas em janeiro atingiram os melhores resultados nos três substratos. Isto evidencia que as sementes colhidas de março e abril, que foram atacadas pelo percevejo $P$. torridus, além de terem sofrido déficits nas taxas de germinação, apresentaram também baixo vigor e menores crescimentos quando comparados com as de janeiro.

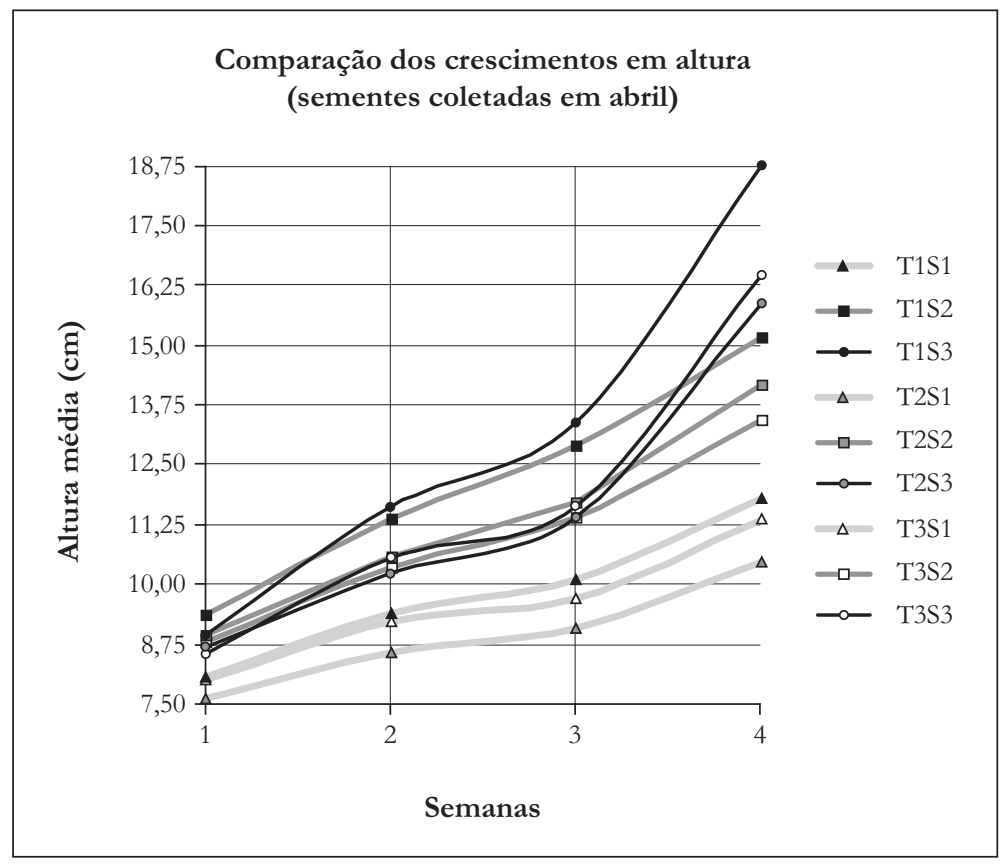

Gráfico 5 - Comparação do crescimento em altura, ao longo de quatro semanas, nos diferentes tratamentos

Rev. Acad., Ciênc. Agrár. Ambient., Curitiba, v. 8, n. 2, p. 205-223, abr./jun. 2010 
Analisando a interação entre os fatores (Tabela 5), observa-se que a influência das sementes foi diferente para os substratos. Quando plantada no substrato 1, tanto a semente de janeiro quanto a de abril foram estatisticamente semelhantes e superiores à semente de março. Já nos substratos 2 e 3 , as sementes de janeiro foram superiores estatisticamente às demais. As sementes de março e abril apresentaram os piores resultados, não diferindo entre si. Quando analisado o efeito dos substratos dentro de cada lote de semente (A, B, C), os resultados foram diferentes para todos os lotes, sendo que os melhores resultados foram atingidos pelas mudas produzidas no substrato 3, seguidos por aqueles atingidos pelos substratos 2 e 1 , todos diferindo entre si estatisticamente.

Tabela 5 - Altura $(\mathrm{cm})$ das mudas em função dos lotes de sementes e dos substratos

\begin{tabular}{lccc}
\hline Meses & Substrato 1 & Substrato 2 & Substrato 3 \\
\hline T1 - Sem. janeiro & 11,80 a C & 15,19 a B & 18,78 a A \\
T2 - Sem. março & 10,48 b C & $14,19 \mathrm{~b} \mathrm{~B}$ & $15,88 \mathrm{~b} \mathrm{~A}$ \\
T3 - Sem. abril & 11,36 a C & $13,45 \mathrm{~b} \mathrm{~B}$ & $16,47 \mathrm{~b} \mathrm{~A}$ \\
\hline
\end{tabular}

Nota: Médias seguidas de letras iguais maiúscula nas linhas e minúsculas nas colunas não diferem ao nível de $5 \%$ pelo teste de Tukey.

Os diâmetros de colo foram menores apenas nos indivíduos plantados no substrato 1, (terra). No restante houve uma média de $0,91 \mathrm{~cm}$, tendo os indivíduos procedentes das sementes de janeiro (T1) apresentado as maiores médias $(0,97$ e 0,95$)$ nos substratos 2 e 3 respectivamente, conforme está apresentado na Tabela 6.

Tabela 6 - Distribuição das médias de diâmetro de colo nas quatro semanas analisadas

\begin{tabular}{lcccc}
\hline & \multicolumn{4}{c}{ Médias } \\
\cline { 2 - 5 } Tratamentos & \multicolumn{4}{c}{ Diâmetro de colo (cm) } \\
\cline { 2 - 5 } & \multicolumn{4}{c}{ Semana } \\
\cline { 2 - 5 } & $\mathbf{1}^{\mathbf{a}}$ & $\mathbf{2}^{\mathbf{a}}$ & $\mathbf{3}^{\mathbf{a}}$ & $\mathbf{4}^{\mathbf{a}}$ \\
\hline T1S1 & 0,50 & 0,53 & 0,62 & 0,78 \\
T1S2 & 0,57 & 0,63 & 0,73 & 0,97 \\
T1S3 & 0,51 & 0,61 & 0,71 & 0,95 \\
T2S1 & 0,48 & 0,50 & 0,57 & 0,73 \\
T2S2 & 0,54 & 0,60 & 0,68 & 0,90 \\
T2S3 & 0,49 & 0,57 & 0,65 & 0,89 \\
T3S1 & 0,49 & 0,54 & 0,61 & 0,76 \\
T3S2 & 0,53 & 0,59 & 0,68 & 0,90 \\
T3S3 & 0,50 & 0,58 & 0,66 & 0,90 \\
\hline
\end{tabular}

Rev. Acad., Ciênc. Agrár. Ambient., Curitiba, v. 8, n. 2, p. 205-223, abr./jun. 2010 
O vigor das mudas produzidas pelos substratos 1, 2 e 3 pode ser observado nos canteiros apresentados na Figura 12.
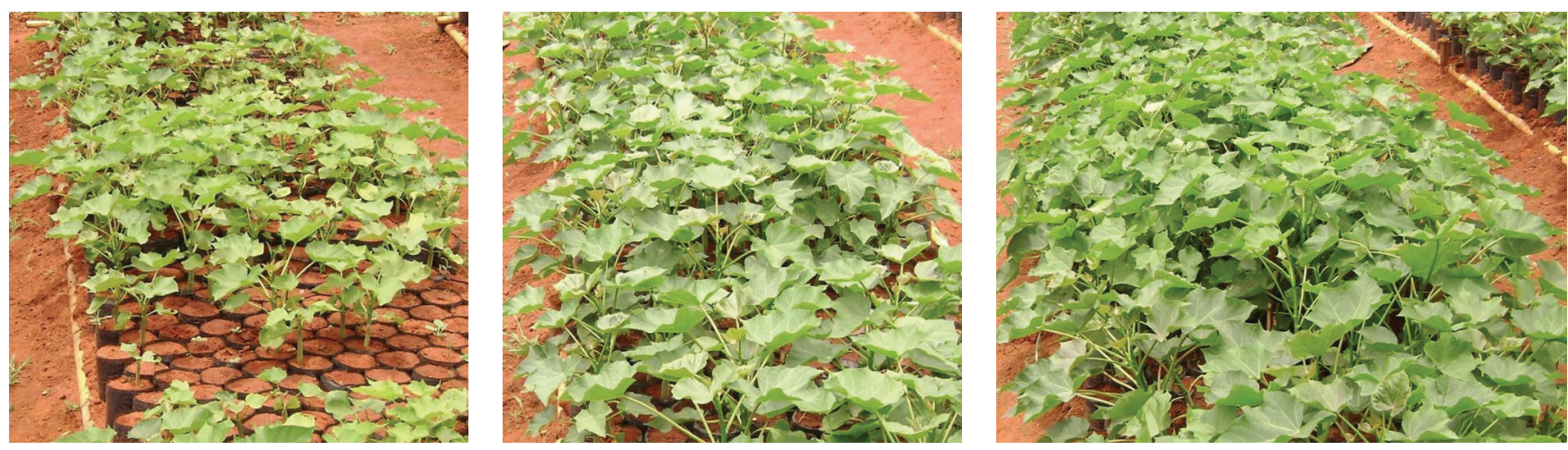

Figura 12 - Mudas produzidas nos substratos 1, 2 e 3, respectivamente

\section{Resultados do experimento 3}

Os dados colhidos foram submetidos a uma análise de variância de fator único. De acordo com a Tabela 7, não houve diferenças estatísticas para o fator analisado. O valor de F calculado (1,33) foi inferior ao tabelado $(2,87)$.

Tabela 7 - Quadro da análise de variância

\begin{tabular}{lrrrrrr}
\hline ANOVA & \multicolumn{1}{c}{ gl } & MQ & F & Valor - P & F crítico \\
\hline Fonte da variação & SQ & gl & & & & \\
\hline Entre grupos & 28,99 & 3 & 9,66 & $\mathbf{1 , 3 3}$ & 0,28 & $\mathbf{2 , 8 7}$ \\
Dentro dos grupos & 261,32 & 36 & 7,26 & & & \\
\hline Total & 290,31 & 39 & & & & \\
\hline
\end{tabular}

A Tabela 8 mostra a produtividade do látex nos diferentes horários de coleta. Cabe lembrar que esta coleta diária foi feita quando as plantas encontravam-se sem folhas. Resultados diferentes poderão ser encontrados em plantas com folhas.

A produtividade do látex resultou em uma média de $8 \mathrm{ml} / \mathrm{planta} /$ dia, valor considerado muito baixo, o que resulta em uma estimada de produtividade de 13,3 litros por hectare/dia, quando se tem 1.666 árvores por ha, ou seja, o plantio em espaçamento de $3 \times 2 \mathrm{~m}$. Para viabilizar este processo seria necessário um alto valor agregado na comercialização do látex.

Foi observado que a incisão feita nos indivíduos para a extração não resultou em fechamento e cicatrização esperada, o que levou ao aparecimento de pequenas necroses nas aberturas feitas. Dois meses após a coleta efetuada nas plantas, ainda não havia sinais de recuperação tegumentária nas incisões.

Em áreas pobres do vale do Jequitinhonha foi relatado o uso do látex com propriedades medicinais hemostáticas, isto é, com ação cicatrizante (COLETÂNEA..., 2003). 
Tabela 8 - Produtividade de látex por indivíduo ao longo do dia

\begin{tabular}{|c|c|c|c|c|c|c|c|c|c|c|}
\hline \multirow[b]{2}{*}{ Horário } & \multicolumn{10}{|c|}{$\begin{array}{c}\text { Indivíduos } \\
\text { Volume (mL) }\end{array}$} \\
\hline & Ind. 1 & Ind. 2 & Ind. 3 & Ind. 4 & Ind. 5 & Ind. 6 & Ind. 7 & Ind. 8 & Ind. 9 & Ind. 10 \\
\hline \multirow[t]{2}{*}{$8 \mathrm{~h}$} & 10,8 & 7,0 & 7,0 & 7,3 & 9,3 & 5,3 & 6,4 & 8,8 & 7,1 & 12,1 \\
\hline & Ind. 11 & Ind. 12 & Ind. 13 & Ind. 14 & Ind. 15 & Ind. 16 & Ind. 17 & Ind. 18 & Ind. 19 & Ind. 20 \\
\hline \multirow[t]{2}{*}{$11 \mathrm{~h}$} & 3,6 & 12,1 & 9,0 & 11,1 & 8,3 & 4,6 & 12,3 & 12,5 & 7,0 & 8,0 \\
\hline & Ind. 21 & Ind. 22 & Ind. 23 & Ind. 24 & Ind. 25 & Ind. 26 & Ind. 27 & Ind. 28 & Ind. 29 & Ind. 30 \\
\hline \multirow[t]{2}{*}{$13 \mathrm{~h}$} & 2,7 & 3,6 & 5,3 & 9,7 & 3,7 & 9,1 & 8,6 & 7,9 & 4,5 & 11,2 \\
\hline & Ind. 31 & Ind. 32 & Ind. 33 & Ind. 34 & Ind. 35 & Ind. 36 & Ind. 37 & Ind. 38 & Ind. 39 & Ind. 40 \\
\hline $16 \mathrm{~h}$ & 7,4 & 8,0 & 6,6 & 11,8 & 8,2 & 13,0 & 5,0 & 8,0 & 8,5 & 8,9 \\
\hline
\end{tabular}

Existem pesquisas atuais no Programa de Incentivo à Inovação - PII, vinculado à Universidade Federal de Itajubá, para desenvolvimento de medicamentos fitoterápicos cicatrizantes à base de látex de pinhão-manso. A pesquisa está sendo desenvolvida na Faculdade de Medicina da Unifei e coordenada pelo professor Nilo César do Vale Baracho.

\section{Resultados do Experimento 4}

Observou-se que o período caducifólio do pinhão-manso no local iniciou em meados de maio e terminou com uma brotação gregária por volta do dia 4 de outubro.

De acordo com a Tabela 9, a altura média das plantas foi de 2 metros e o número médio de ramificações, de 6,76 ramos por planta. A correlação entre os valores dos dois parâmetros medidos foi de 0,17, o que significa que não existe qualquer relação entre altura e o número de ramificações.

Segundo Saturnino (2005), as inflorescências do pinhão-manso são apicais, portanto cada ramo possui uma inflorescência no ápice e, consequentemente, quanto maior o número de ramos, maior será o número de frutos possíveis por planta.

Tabela 9 - Valores dos resultados analisados

\begin{tabular}{|c|c|c|c|c|c|c|c|c|}
\hline & \multicolumn{2}{|c|}{ Total } & \multicolumn{2}{|c|}{ Parcela 1} & \multicolumn{2}{|c|}{ Parcela 2} & \multicolumn{2}{|c|}{ Parcela 3} \\
\hline & Altura & N. Ram. & Altura & N. Ram. & Altura & N. Ram. & Altura & N. Ram. \\
\hline Média & 2,00 & 6,76 & 2,12 & 6,76 & 1,78 & 5,97 & 2,02 & 8,11 \\
\hline Desvio padrão & 0,32 & 2,28 & 0,30 & 2,28 & 0,32 & 2,52 & 0,22 & 2,48 \\
\hline $\mathrm{CV} \%$ & 15,91 & 33,79 & 14,21 & 33,79 & 18,22 & 42,21 & 10,73 & 30,56 \\
\hline Correlação & 0,17 & & 0,01 & & 0,28 & & 0,18 & \\
\hline
\end{tabular}

Rev. Acad., Ciênc. Agrár. Ambient., Curitiba, v. 8, n. 2, p. 205-223, abr./jun. 2010 


\section{Conclusões}

\section{Conclusões do experimento 1}

O experimento comprovou que as sementes atacadas pelo percevejo $P$. torridus, colhidas em março e abril, atingiram percentagens de germinação muito inferiores àquelas que não sofreram o ataque, colhidas em janeiro. O tratamento que atingiu o melhor resultado ( $\mathrm{PG}=60 \%$ e VfG $=2,64 \mathrm{~s} /$ dia) foi o T1S3, cujas sementes foram colhidas em janeiro e com substrato terra $+20 \%$ esterco $+\mathrm{NPK}$; e o tratamento que atingiu a menor percentagem de germinação foi o T3S2 (PG=21,25\%), cujas sementes foram colhidas em abril e com substrato terra $+25 \%$ M.O. As sementes colhidas em março, independente do substrato analisado, foram as que atingiram menores taxas de velocidade final de germinação.

O ensaio mostra a necessidade de um controle de pragas para a condução de plantios de pinhãomanso com fins de produção de sementes em áreas onde há a presença do $P$. torridus.

\section{Conclusões do experimento 2}

No presente trabalho o substrato com melhores resultados para o desenvolvimento do pinhão-manso foi o 3 (composto de terra $+20 \%$ esterco bovino + NPK $-0,3 \mathrm{~kg} \mathrm{~m}^{-3}$ de super simples, $0,05 \%$ de cloreto de potássio).

O experimento comprovou que as sementes coletadas em março e abril, após o ataque do percevejo $P$. torridus, além de apresentarem percentagens de germinação muito inferiores àquelas que não sofreram o ataque, deram origem também a indivíduos com menores taxas de crescimento.

O melhor tratamento, portanto, foi o integrado pelos indivíduos procedentes da coleta de janeiro, no substrato 3.

\section{Conclusões do experimento 3}

O experimento demonstrou que a planta de pinhão-manso no período caducifólio não apresenta diferença significativa na exudação de látex ao longo do dia.

\section{Conclusões do experimento 4}

Como não houve correlação entre altura e o número de ramificações, isto significa que a quantidade de ramos que um indivíduo possui é um fator que pode ser selecionado geneticamente, com o fito de se aumentar futuramente a produção de sementes por indivíduo.

A medição das alturas de um povoamento é importante para avaliar o crescimento. O presente trabalho contribuiu para um acompanhamento da plantação, quando, a partir dos dados coletados futuramente, poderão se calcular os incrementos anuais da cultura.

\section{Considerações finais}

A espécie Jatropha curcas tem sido alvo de muitas especulações atualmente, em virtude de seu alto potencial como produtor de óleo biocombustível, despertando em diversos setores da sociedade a busca pela independência das fontes de recursos não renováveis, como o petróleo.

O presente trabalho contribuiu para aumentar o volume de informação sobre os dados silviculturais, como germinação de sementes, crescimento, combate a pragas e doenças, e outros tópicos relevantes da cultura do pinhão-manso, bem como para enaltecer a necessidade de pesquisas na área. 


\section{Referências}

BONDAR, G. Insetos daninhos na agricultura, 2. Boletim de Agricultura, v. 14, p. 434-470, 1913.

CARVALHO, C. M.; CASTRO, A. G.; CÂNDIDO, D. M. Avaliação da germinação em viveiro da espécie Jatropha curcas L. (pinhão-manso) de distintas procedências. In: WORKSHOP INTERNACIONAL BRASIL - JAPÃO: BIOCOMBUSTÍVEL, MEIO AMBIENTE E NOVOS PRODUTOS DA BIOMASSA, 5., 2007, Campinas, SP. Anais... Campinas, SP: Unicamp, 2007.

COLETÂNEA sobre o pinhão-manso, 2003. Disponível em: <http://www.epamig.br/index>. Acesso em: 26 out. 2008 CORAIOLA, M. Caracterização estrutural de uma Floresta Estacional Semidecidual localizada no Município de Cássia-MG. 1997. 196 f. Dissertação (Mestrado em Engenharia Florestal) - Universidade Federal do Paraná, Curitiba, 1997.

CORAIOLA, M.; PÉLLICO NETTO, S. Análise da estrutura dimensional de uma floresta estacional semidecidual localizada no município de Cássia-MG: estrutura diamétrica. Revista Acadêmica: Ciências Agrárias e Ambientais, v. 1, n. 3, p. 11-24, 2003.

COSTA LIMA, A. C. Insetos do Brasil: hemípteros. Rio de Janeiro: Escola Nacional de Agronomia, 1940. (Série Didática, n. 3).

DRUMMOND, O. A.; PURCINO, A. A. C.; CUNHA, L. H. de S. et al. Cultura do pinhão manso. Belo Horizonte: EPAMIG, 1984. (EPAMIG. Pesquisando, 131).

MARTIUS, C. F. P. von; EICHLER, A. W.; URBAN, I. Flora brasiliensis, 1874. v. XI, parte II, p. 487-488, Disponível em: <http://florabrasiliensis.cria.org.br/taxonCard?id=FB9775>. Acesso em: 11 nov. 2008.

FROESCHNER, R. C. Family Scutelleridae Leach, 1815. The shield bugs. In: HENRY T. J.; FROESCHNER, R. C. (Ed.). Catalog of the Heteroptera or true bugs, of Canada and the Continental United States. New York: E.J. Brill, 1988. p. 684-693.

GALLO, D. et al. Manual de entomologia agrícola. São Paulo: Ceres, 1988.

HENNING, R.; VON MITZLAFF, K. Produktion und Nutzung von Purgieröl als Kraftstoff und Rohstoff für die lokale Seifenherstellung im Sahel. Der Tropenlandwirt, v. 53, p. 137-151, 1995.

LORENZI, H. et al. Árvores exóticas no Brasil: madeireiras ornamentais e exóticas. Nova Odessa, SP: Plantarum, 2003.

KARMEGAM, N. et al. Indigenous-plant extracts as larvicidal agents against Culex quinquefasciatus Say. Bioresource Technology, v. 59, p. 137-140, 1997.

MENGUE, S. S.; MENTZ, L. A.; SCHENKEL, E. P. Uso de plantas medicinais na gravidez. Revista Brasileira de Farmacognosia, v. 11, p. 21-35, 2001.

MONTE, O. Algumas variações nos desenhos e cores de Pachycoris torridus (Scopoli). O Campo, v. 8, n. 85, p. 71, 1937.

OPENSHAW, K. A review of Jatropha curcas: an oil plant of unfulfilled promise. Biomass and Bioenergy, n. 19, p. 1-15, 21, 2000.

PRAMANIK, K. Properties and use of Jatropha curcas oil and diesel fuel blends in compression ignition engine. Renewable Energy, n. 28, p. 239-248, 2002.

PROGRAMA de Incentivo à Inovação - PII UNIFEI, outubro de 2007. Itajubá: Universidade Federal de Itajubá. Disponível em: <www.pii.unifei.edu.br/index.html>. Acesso em: 11 nov. 2008.

SATURNINO, H. M. Espécies oleaginosas para produção de biodiesel na Agricultura Familiar. EPAMIG, v. 26, p. 1-73, 2008.

SATURNINO, H. M. et al. Cultura do pinhão-manso (Jatropha curcas L.). Informe Agropecuário, v. 26, p. 44-78, 2005. 
SCHUH, R. T.; SLATER, J. A. True bugs of the world (Hemiptera: Heteroptera) classification and natural history. New York: Cornell University Press, 1995.

SEVERINO, L. S.; LIMA, R. de L. S. de; BELTRÃO, N. E. de M. Germinação e crescimento inicial de mudas de pinhão-manso em função do peso da semente. Campina Grande: Embrapa Algodão, 2006. Comunicado técnico.

SOLSOLOY, A. D. Pesticidal efficacy of the formulated physic nut, Jatropha curcas L. oil on pests of selected field crops. Philippine Journal of Science, v. 124, p. 59-74, 1995.

SOTO, S. S.; MILANO, P.; NAKANO, O. Nova planta hospedeira e novos padrões cromáticos de pachycoris torridus (Scopoli) (Hemiptera: Scutelleridae) no Brasil. Neotropical Entomology, v. 33, p. 109-111, 2004.

Recebido: $21 / 01 / 2010$

Received: 01/21/2010

Aprovado: $25 / 03 / 2010$

Approved: 03/25/2010 